\title{
Prosthodontic Rehabilitation of Acquired Maxillofacial Defects
}

\author{
Sneha Mantri ${ }^{1}$ and Zafrulla Khan ${ }^{2}$ \\ ${ }^{1}$ Hitkarini Dental College and Hospital, Jabalpur, \\ 2James Graham Brown Cancer Center Louisville, Kentucky, \\ ${ }^{1}$ India \\ ${ }^{2} U S A$
}

\section{Introduction}

In the last two decades treatment for head and neck cancers has evolved with multiple modality treatments, including radiation and chemotherapy in an effort to enhance local and regional disease control, reduce distant metastasis, preserve anatomic structures , and improve overall survival and quality of life (QOL). Surgery is first choice for early cancers and for cancers that do not respond to radiation and chemotherapy in the form of salvage (Maureen, 2004).

Surgery can result in cosmetic, functional and psychological impairment greatly affecting the patient's quality of life (Roger, 2010). Presently the thrust in cancer care is not simply on survival but on rehabilitation, which aims to improve multiple impairments and QOL. Health related QOL refers to a multidimensional concept, which encompasses perception of both negative and positive aspects of at least four dimensions of physical, emotional, social and cognitive function (Moser et al., 2003).

Rehabilitation of such patients is quiet challenging and requires multidisciplinary team for comprehensive care and optimal post treatment functional outcomes. (Dingman, et al., 2008, Lemon et al., 2005, Logman, 1998, Hubalkowa, 2010). The team usually comprises of otorhinolaryngologist, radiation oncologist, medical oncologist, maxillofacial prosthodontist, speech therapist, psychologist, social workers, and nursing staff amongst the other disciplines for specific problems of the cancer patient. As a critical member of the team the maxillofacial prosthodontist co-ordinates the effort in many facets of patient care. Treatment is patient centered and patient directed, individualized to meet each patient's unique and specific needs.

Rehabilitation goals are focused on the restorative, supportive, palliative and preventive aspects of treatment (Moser, et al., 2003). Advanced cancers or trauma destroying structures, which may include soft and hard tissues of jaws, facial skeleton, oral tissues, lips, checks, nose and eyes, can affect the maxillofacial region. The defect may result in oroantral, oronasal, oronasal-orbital communication. The primary objective of rehabilitation is to preserve and restore the function of speech and swallow, preludes to the image restoration 
and boosts confidence of the patients so they can return to society; who have suffered the ravages of disfigurement.

\section{Psychosocial intervention}

The psychosocial effects of head and neck cancer are profound. Head and neck cancer strikes at some of the most basic human functions such as speech, taste, breathing, diet changes including facial disfigurement.This traumatic experiences poses great emotional threat to the patient and hinders their capacity to lead a normal life. The combination of exacerbated psychological distress and maladaptive coping strategies leads to impaired functioning and decreased rating of overall QOL (Haman 2008).

In specific reference to cancer, distress is defined as an unpleasant emotional experience of a psychological (cognitive, behavioral, emotional), social and / or spiritual nature that interferes with the ability to cope effectively with cancer, its physical symptoms and its treatment. Distress extend along a continuum, ranging from normal feelings of vulnerability, sadness and fears to problems that can become disabling, such as depression, anxiety, panic, social isolation and essential spiritual crisis (NCCN Practice Guidelines in Oncology 2005, as cited by Haman 2008).

An oncology social worker may help patients by providing access to valuable community resources and psychological assessment and intervention like head and neck support groups, which include other patients with similar cancers. Issues concerning treatment expectations, adjustment to diagnosis and coping strategies, during pretreatment counseling can reduce patient's uncertainty and help to restore their sense of control (Breitbart et al., 1988). The understanding of the psychological implications plays an important role in the management of patients with jaw defects (Rosenthal, 1964 as cited by Gillis, 1979). The primary goal should be to treat the person rather than just the defect (Lehman W.L. et.al. 1966 as cited by Gillis, 1979).

Rehabilitation is to help to readapt a disabled person to society, but ultimately it is the society that must be rehabilitated to reduce its prejudice, foster inclusiveness and increase acceptance of difference (Hearst, 2007).

\section{Scope of prosthodontic services in rehabilitation of maxillofacial complex}

Maxillofacial prosthetic services is to rehabilitate individuals who suffer anatomical compromise due to congenital disorders, trauma and oral/facial malignancies. Head and neck cancer patient presents a wide array of rehabilitative challenges associated with speech, mastication, deglutition and esthetics. Maxillofacial prosthetic treatment is not a substitute for plastic and reconstructive surgery, in certain circumstances it may be an alternative. Maxillofacial prosthesis provides a nonsurgical treatment for patients who are not good candidate for plastic surgery intervention because of advanced age, poor health, very large deformity or poor blood supply due to radiation. Moreover prosthetic treatment is indicated when anatomical structures of head and neck are not replaceable by living tissue, when recurrence is likely, when radiotherapy is administered or when fragment of fractured bones are severely displaced. (Chalian et al., 1972). Prosthodontic rehabilitation has specific advantages since it requires little or no additional surgery and the results are 
often more esthetically pleasing and less invasive than plastic surgery. The primary objectives of maxillofacial prosthetics and rehabilitation are to construct a prosthesis, which will restore the defect, improve function, enhance esthetics, return the patient back to society and thereby boost the morale of the patient contributing to the quality of life of the cancer patient.

\section{Role of Maxillofacial prosthodontist as a member of multidisciplinary team}

The role of maxillofacial prosthodontist varies depending on the modality of treatment. As a critical member of the multidisciplinary team, the maxillofacial prosthodontist co-ordinates the efforts in many facet of patient care. The prosthodontist must be acutely alert towards the medical health of the patient and be familiar with the various hospital protocols. He is best qualified to provide prosthetic support to the surgeon by preparing facial moulages and surgical stents to aid postoperative recovery. Communication with the surgeon as far as extent of disease, precise surgical technique, anticipated postoperative defects and healing time could help to plan the treatment. Recommendations can be made for the preservation of tissues or to improve the existing anatomical structures to improve the retention, stability and support for the prosthesis. (Zlotolow, 2001) Similarly, interaction with the radiation oncologist can render opinion regarding oral and dental condition, and recommended extraction of teeth, maintenance of teeth post radiation since the radiation might modify the care of teeth and mouth. Co-ordination with speech pathologist to gain knowledge about mechanics and physiology of speech can help to design the prosthesis, which can fulfill the requirements of resonance, phonation and articulation. (Chalian et al., 1972). Other specialists should be consulted as and when required. Primary concern of the treatment is to assure that the oral cavity is prepared to reduce the potential untoward effects of cancer treatment. The patients should be educated regarding the possible short term and long-term complications of chemotherapy and radiotherapy, trained in oral hygiene methods and therapeutics for oral health preservation and rehabilitate the post surgical defect utilizing prosthesis. Long term follow up and evaluation with an eye to the possibility of lesion recurrence is a part of the crucial contribution by the prosthodontist (Khan Et.al., 2006).

\section{Presurgical prosthodontic intervention}

A comprehensive oral and dental examination should be part of the presurgical intervention. The success of prosthetic treatment for a head and neck cancer patient may depend on the accuracy and adequacy of pre-surgical records. Presurgical records such as articulated diagnostic cast, jaw relation records, profile template of the midline of face, matching tooth shape and shade, radiographs, photographs of the mouth and face from strategic angles, facial moulage may be obtained for optimum post treatment outcome. Elimination of existing local infection, extraction of teeth with poor prognosis, restoration of teeth that has to be retained to support the prosthesis, modification of oral structures to anticipate the needs of subsequent treatment procedures such as alveoloplasty, gingivoplasty etc. may be required, as time permits. Existing dental prosthesis may be modified to serve as treatment prosthesis or preparation of surgical stents. Thus, an optimum oral environment should be maintained in order to provide freedom from infection and facilitate early recovery of tissues (Davenport, 1996, Jerbi, et al., 1968) Nutritional and psychological assessment and intervention should be included in the protocol. 
Factors influencing the prognosis of prosthetic rehabilitation are size of the defect, availability of hard and soft tissues in the defect area to provide support for the prosthesis, proximity of vital structures, patient's attitude, temperament, systemic conditions and the patient's ability to adapt to the prosthesis. (Desjardins, 1978, Brown, 1970). Thus providing education, increasing awareness on possible changes, building of rapport and a working relationship with patients and their families are crucial during the pretreatment phase (Dingmam, et.al. 2008).These days CAD/CAM technology can be utilized in preprosthetic planning to prepare facial moulages and fabricate surgical stents for precise placement of implants when indicated.

\section{Postsurgical prosthodontic rehabilitation of acquired defects}

Head and neck cancer patients undergoing surgical resection as primary modality of treatment require prosthetic rehabilitation for restoration of speech deficits, control of oral secretions, mastication and swallowing dysfunction and possibly restoration of facial disfigurement. These defects can be divided into maxillary and mandibular defects.

\subsection{Maxillary defects}

Acquired defects of the palate may be due to surgery and or trauma. The defect may be in the form of a small opening resulting in communication from the oral cavity into the maxillary sinus, or it may include portion of the hard and soft palate, alveolar ridge and the floor of the nasal cavity (Chalian 1971).

Post surgical maxillary defects predispose the patient to hypernasal speech, fluid leakage through the nose including possibility of aspiration and impaired masticatory function (Keyf, 2001).The prosthesis constructed to repair the defect is termed as a maxillary obturator. An obturator (Latin; Obturare, to stop up) is a disc or plate used to close an unnatural opening or defect. The placement of an obturator restores oronasal separation to allow an increase in intraoral pressure and a decrease in nasal airflow rate. (Yoshida H., et.al. 2000). Obturators provide immediate improvement in speech articulation and intelligibility, voice quality and swallowing that approximates pre-surgical function enabling the patient to eat and drink immediately. Possible support is provided to the orbital content to prevent enopthalmous and diplopia, lips and cheeks are supported to restore the midfacial contour to improve the esthetics (Wang, 1997).Obturators are constructed in three phases, fulfilling different objectives in each phase.

\subsubsection{Surgical obturator}

It is constructed from pre operative cast after determining the approximate surgical boundaries of resection preoperatively by consulting the surgeon. At this point, it is an approximate guess relying on radiographic findings (Figure1a\&b). The surgical obturator is inserted and sutured, screwed or wired at completion of resection. It separates the oral and nasal cavities, provides support for surgical packing, supporting the split thickness skin graft if used, minimizes wound contamination, enables the patient to speak and swallow immediately after surgery (Huryn, 1989). 


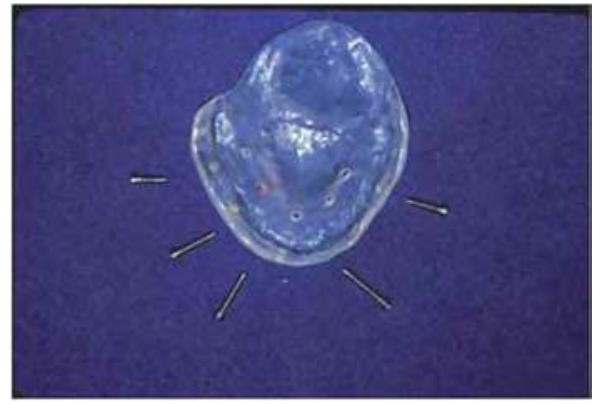

(a)

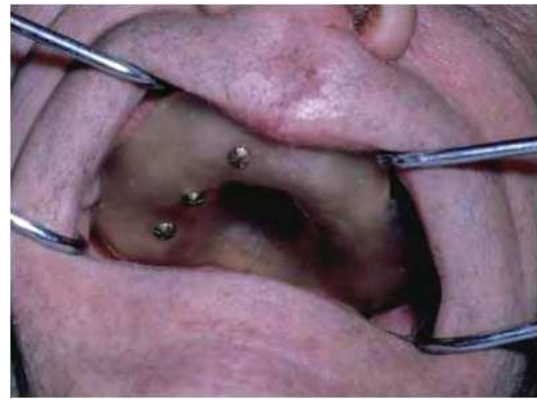

(b)

Fig. 1. (a) Surgical Obturator with bone screws (b) Obturator screwed after resection

\subsubsection{Interim/provisional obturator}

The surgical obturator sometimes can be modified to compensate for tissue changes or surgical defect, which is different from the pre-surgical determination to form the provisional obturator. Usually it is constructed from post surgical impression to accurately reflect the defect. It replaces the surgical obturator and is worn in the postoperative healing period. The interim prosthesis in addition to clasps for retention can have anterior teeth for esthetics and a flange for lip and cheek support, which contributes to the patient's well being and social integration. Use of molar teeth is avoided to minimize occlusal pressure on the defect. The obturator is relined periodically for better adaptation as the healing progress. Good oral hygiene is encouraged during the healing phase. (Martin, 1993)

\subsubsection{Definitive obturator}

It is a more permanent prosthesis designed and fabricated when the surgical site is stable usually between six months to a year and local recurrence is ruled out. Precise impression of the defect is made for the fabrication of the prosthesis that allow maximum distribution of forces to all available teeth if present, remaining hard palate, lateral walls of the defect and remaining alveolus. In addition, occlusal relationship must be obtained to make the prosthesis cosmetic as well as functional (Fig.2a, b, c \&d). Obturator bulbs for large defects can be made hollow to reduce the weight on the surgical side and improve retention of the prosthesis and comfort of the patient. (Payne,et al., 1965, Ampil, et al., 1967, Brown 1969, Chalian,et al., 1972, Buckner 1974, Benington,et al., 1982, Wiv ,et al., 1989, Wang,et al., 1999, McAndrews, et al., 1998 as cited by Keyf 2001).

\subsubsection{Consideration for management of edentulous patients}

Fabrication of an obturator for the edentulous patients provides major challenge because of the lack of support from teeth and lack of suction. In addition, excess resorption of the residual edentulous ridges may be encountered, demands equalization of stress distribution to available portions of the palate. In such conditions retention stability and support can be enhanced by maximum preservation of hard palate, skin grafting the cheek and maxillary sinus wall for better support and removal of inferior turbinates to provide a larger surface area for stress distribution (Jackob, et al., 2000). 


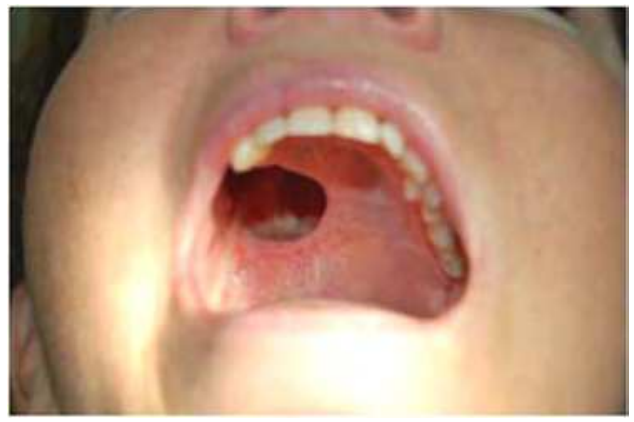

(a)

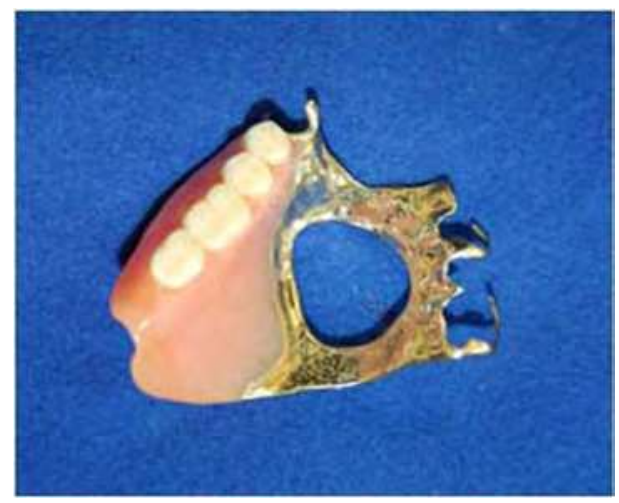

(c)

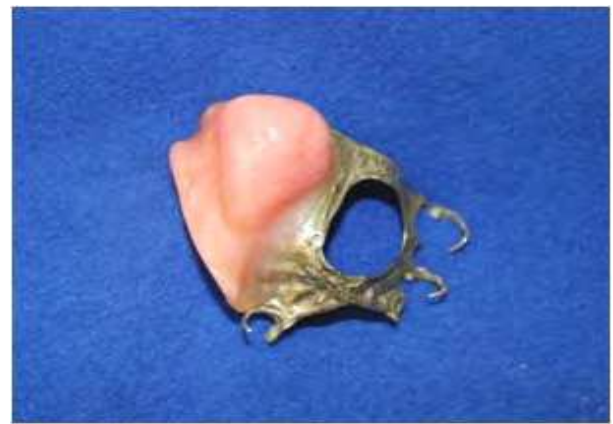

(b)

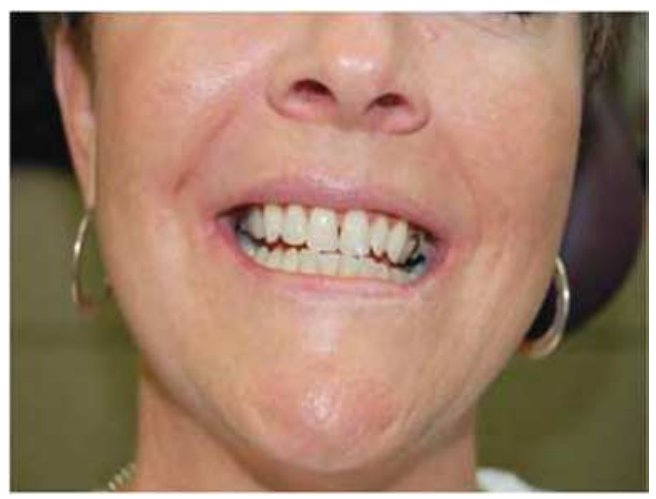

(d)

Fig. 2. (a) Hard Palate Defect (b) Partial denture definitive obturator

(c) Prosthesis replacing missing teeth (d) Prosthesis restoring esthetics and function

\subsubsection{Hygiene considerations}

Patients using an obturator must conduct meticulous daily cleaning of the defect and the prosthesis to prevent malodor and infection. As most patients remain with a resection, cavity, which allows the nasal and oral cavities to communicate, collection of mucous, and blood become encrusted and colonized by anaerobic bacteria in the area resulting in foul smell, nasal obstruction and discomfort. As the normal mucociliary, apparatus is no longer able to clear the secretions patients must be taught to clean and maintain the cavities themselves (Odell.et al., 2007). When teeth are present, high level of oral hygiene should be maintained especially for patients who exhibit xerostomia and have an increased risk of caries. Fluoride application and professional cleaning are mandatory (Fig.3).

\subsection{Management of soft palate defects}

Prosthesis for soft palate defects varies based on the extent and site to attain velopharyngeal closure during functions such as speaking and swallowing. Palatopharyngeal closure 


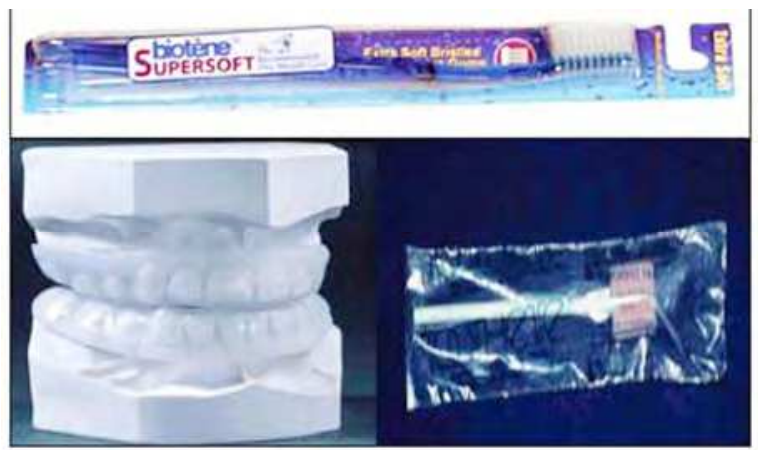

Fig. 3. Custom fluoride trays, soft toothbrush and toothette for cleaning teeth

normally occurs when the soft palate elevates and contacts the lateral and posterior pharyngeal walls of the nasopharynx. Acquired defects of soft palate results in insufficient tissues or altered function of the remaining structures to provide palatopharyngeal closure.

Prosthesis to aid in correcting palatopharyngeal insufficiency can be accomplished by providing pharyngeal obturator/speech bulb prosthesis. A portion of obturator extends into the pharynx to separate oropharynx and nasopharynx, restores the soft palate defect and allows adequate closure of palatopharyngeal sphincter (Abrew, et.al., 2007, Saunders, 1993, Beumer, et.al., 1996 as cited by Tuna, et al. 2010).

A meatus obturator is designed to close the posterior nasal chonchae through a vertical extension from the distant aspect of the maxillary prosthesis. (Eckert, et.al. 2000). This obturator design may be indicated when the entire soft palate has been lost in an edentulous patient.

Palatal lift prosthesis is provided for patients with speech disorders due to palatopharyngeal incompetency normally caused by closed head injuries. The purpose is to elevate the soft palate to the level of the palatine plane, enabling velopharyngeal closure by the actions of pharyngeal walls thus improving the quality of speech and reducing the effort required to speak (Gonzalez, 1970, Gibbons, et al., 1958).A speech pathologist is involved in training a patient to use the prosthesis to advantage. Palatal lift prosthesis cannot function by itself, but compliments a speech therapists training for the patient.

\subsection{Defects of mandible, tongue and associated structures}

Treatment of mandibular defects includes, defect from surgical resection of mandible, tongue, floor of mouth and associated structures. Disabilities resulting from such resection include impaired speech articulation, difficulty in swallowing, trismus, deviation of mandible during functional movement, poor control of salivary secretions and severe cosmetic disfigurement, (Beumer,etal.,2003 ). Based on the amount of resection or extent of bone loss, mandibular defects can be classified as continuity and discontinuity defects. Mandibular discontinuity can be managed by immediate on delayed surgical reconstruction to re-establish continuity. Loss of mandibular continuity if not re-established alters the symmetry of mandible, leading to altered mandibular movement and deviation of the residual mandible towards the affected side. Different methods used to reduce mandibular 
deviation are intermaxillary fixation, mandibular guidance appliances, sectional dentures or resection prosthesis. Resection prosthesis may require use of a guide flange or a maxillary occlusal platform incorporated in the prosthesis to guide the mandibular segment into optimal occlusal contact. This prosthesis is made four to six weeks after cancer surgery, after initial healing is complete and the patient is able to open and close the mouth adequately. Mandibular exercise regimen is advocated simultaneously.

According to Beumer and Curtis, intemaxillary fixation is most useful in patients with resection confined to the mandible with little soft tissue loss. The design of mandibular guidance prosthesis for partially edentulous mandible incorporates a rigid major connector, occlusal rest, guide planes and obtains major support from adjacent teeth and soft tissues. In edentulous patients, the dentures are extended into the soft tissue for added stability. An occlusal ramp is added to the palatal side of the maxillary denture to guide the mandible into proper occlusion. The severity of disabilities combined with composite resection of tongue, floor of the mouth and mandible is greatly reduced by the introduction of micro vascular free flap and possible osseointegrated implants depending on the amount and areas receiving radiation. A free tissue transfer with the fibula allows the possible placement of dental implants to support resection prosthesis. (Zlotolow, 2001)

\subsubsection{Glossectomy defect}

When a patient undergoes a partial on total glossectomy, the ability to masticate, swallow and formulate vowels and consonants for speech sounds is dramatically altered. The size, location and extent of the defect affect the degree of disability to swallow or speak. The areas of surgical resection that affects function of the tongue include removal of the anterior tip of the tongue, lateral (partial) glossectomy, removal of the base of the tongue and total glossectomy. Moore (1972) as cited by Zaki H.S., suggested tongue prosthesis as the treatment of choice in total glossectomy. This approach seldom restores the function of speech and swallow; it is mostly cosmesis. An artificial tongue of either hard or resilient acrylic is attached to the lower denture base, which covers the alveolar ridge as well as floor of the mouth. The artificial tongue is designed in such a way that the dorsum of the anterior two third of the tongue conforms to the anterior of the palate and comes almost in contact with the palate when the teeth are brought into occlusion. The posterior one third of the tongue is designed to act as a funnel, which directs the food and fluids into the oesophagus. Palatal augmentation (or drop) prosthesis is indicated when the tongue resection and reconstruction results in limited bulk and restricted movement of the reconstructed tongue resulting in reduced tongue palate contact. The palatal augmentation prosthesis allows reshaping of the hard and /or soft palate to improve tongue/palate contact during speech and swallowing. This could be a removable partial denture or complete denture prosthesis. (Laaksonen J.P. et al. 2009).

While rehabilitating a glossectomy patient the oral functions of the residual structures must be assessed. In addition to the extent of the defect factors such as mobility of the residual oral and paraoral structures, neuromuscular co-ordination and motivation will also determine the prognosis of the case.

\section{Extraoral facial defects}

The face is the most prominent visible part of the body and provides sense of identity to a person. Functionally, it animates emotion, communicate and intellect and provide the 
essential access routes to the respiratory and gastrointestinal system. Cognitively the region is the sole source of vision, hearing, taste and smell. Thus, facial disfigurement whether congenital or acquired has the potential to cause multiple problems and psychosocial dysfunction (Dropkin, 1999, Sarwer, Thompson, 2001 as cited by Wallace 2008). Such patients with facial disfigurement spend significant portions of their lives dealing with stigma. Stigma is a mark of disgrace attached to people who are considered different. When the actual social identity is perceived as departing from normality the individual is reduced in our minds from a whole and usual person to a tainted, discounted one "Such an attribute is stigma (Goffman 1963 as cited by Bonanno et.al., 2010). Stigmatized and socially excluded their ability to interact is often distorted and interaction is the source of problems including verbal and physical abuse, ridicule hostile behavior and isolation (Kish et.al. 2000, Furness et.al. 2006, Hagedoorm, t.al. 2006 as cited by Bonaeno, et.al. 2010).

Facial defects can be restored either surgically or prosthetically depending on the location and size of the defect, the surgeon is limited by the availability of tissues, changes due to radiation and the need for future visual evaluation for recurrent cancer.

Prosthetic restoration of facial defects is a combination of art and science requiring multidisciplinary approach focusing on the area involved for rehabilitation such as an eye, ear, nose or midface. A prosthetic replacement of an exterior part is termed as epithesis, which is described as early as seventh century (Van Doorne, 1994). There are definite limitations of both treatment modalities. The material available for facial restoration, movable tissue bed, limits the prosthodontist in retaining a large prosthesis and patient's willingness to accept the restoration (Beumer, et.al. 2003).

Prosthetic replacement of missing facial tissues has several advantages over surgical reconstruction. The process is relatively inexpensive, allows for periodic evaluation and cleaning of the site. It is a short process and the maxillofacial clinician has complete control of color, shape and position of the prosthesis. Disadvantages include possible irritation of he tissue site need for periodic remake and depending on adhesive on some other form of retention (Lemon, et.al. 2005). The goal of facial rehabilitation is to provide a natural, life like, integrated, esthetically pleasing, anatomically correct prosthesis, which blends with the body specially the surrounding structures. Knowledge of material science is the key to provide best care for patients.

\subsection{Materials used for maxillofacial prosthesis}

Desirable properties of a maxillofacial prosthetic material includes durability, biocompatibility flexibility light weight, color stability, hygiene, thermal conductivity, ease of fabrication and use, texture, availability and cost (Beumer, et al., 1996). Ambroise Pare who made varied contribution to standardize the indications for and material used in facial prosthetics. Amongst the large number of materials that have been tried out in the history of Anaplastology, example porcelain, natural rubber, gelatin and latex, two have established themselves, Methyl Methacrylates and Silicones (Andres, 1992). Methacrylates are relatively hard and more durable. Silicones are soft and flexible. Dr. Tsun Ma in a clinical overview of the materials stated that amongst the commercially available materials none of them is considered ideal. Different elastomers have their own physical and mechanical properties and share common clinical problem such as 1) discoloration over time (intrinsic and extrinsic discoloration due to environmental factors and loss of external pigments) and 2) 
degradation of physical and mechanical properties (tear) at the margin, lack of compatibility with medical adhesives, weakening of margins by colorants, adhesives, solvents and cleansers and deterioration of static and dynamic mechanical properties. Most discoloration and tear occurs when patients remove prosthesis or adhesives (Khan et al., 1992). Over the years there has been some improvement in facial biomaterials; but still there exists a clear need for new or improved facial materials in all clinical situations. (Lemon et.al. 2005).However studies have shown that chlorinated polyethylene may have advantage over conventional silicone rubber material in its ability to be repaired, relined or reconditioned, extending the life of the prosthesis. In addition, it can be used with any adhesive type. It has greater edge strength, does not support fungus growth and is cost effective as compared with silicone materials except processing of this material is complex and difficult (Gettleman et.al. 2004, Gettleman 1992, Gettleman et.al. 1989, Gettleman et.al. 1987, Gettleman et.al. 1985, as cited by Lemon et.al. 2005).

\subsection{Types of extraoral prosthesis}

These prostheses may include orbital/ocular, auricular, nasal or combination including midfacial prosthesis. The construction of facial prosthesis consists of four stages each equally important to the success of the rehabilitation effort and each requiring meticulous attention to detail (Andres,et al., 2000) Moulage impression and working cast fabrication, sculpting and formation of the pattern, including color match, mold fabrication and processing of the prosthesis with intrinsic and extrinsic coloration.

\subsubsection{Auricular}

Prosthetic replacement of the missing or altered ear can provide excellent cosmetic results. The advantage of an auricular prosthesis relates to the lateral face position and the effort to use hair to conceal the superior and posterior margin. When an auricular prosthesis is indicated, the entire ear should be removed except for the tragus. It provides a landmark for repeated placement since it is not easily displaced and helps to hide the anterior margin of the prosthesis (Carr, 1998). It also makes it easy for the patient in placement of the prosthesis especially if adhesives are used. Replacement of a complete ear is easy since it allows complete freedom of shape, size and location. The recipient areas should be flat or concave. Convexities from excessive bulk can hamper esthetic results (Parr et al. 1981 as cited by Lemon et al. 2005). Skin devoid of hair provides good adhesion base yet a split thickness graft is advantageous. Tissue pockets assist in the orientation and stability of the prosthesis and allow the margins to extend in a zero degree emergence profile. Craniofacial implants specifically designed to be placed in the mastoid temporal bone permit positive retention for auricular prosthesis and the ease of placement. (Fig.4a\&b)

\subsubsection{Nasal}

Since nose is very prominent, centrally located and difficult to disguise on the face, making prosthesis with realistic effect is of vital significance. Presurgical photographs can aid for accurate replication of the patients original nose preservation of nasal bone to provide retention and support should be emphasized. Maintaining the anterior nasal spine helps to determine the final position of lip (Marunick, et al. 1985 as cited by Lemon, et al., 2005). 


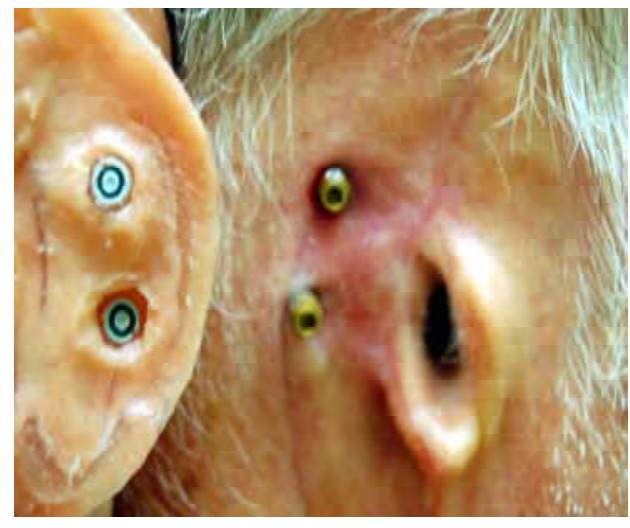

(a)

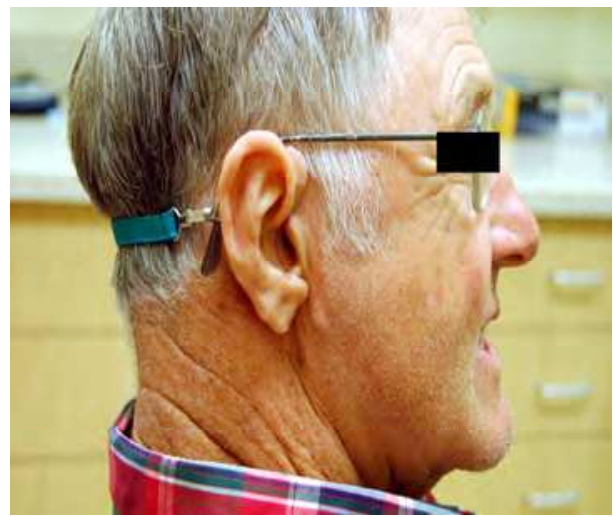

(b)

Fig. 4. (a) Two Implants placed in mastoid/temporal region (b) Implant retained Silicone Auricular prosthesis

Attempts should be made to camouflage the margin with the surrounding anatomy and match the color, texture and translucency of skin. If cranio-facial implants are indicatedpreferred site for implant placement is the anterior floor of the nose and maxilla region, which provides greatest bulk for the superstructure and retention mechanism (Carr, 1998).

\subsubsection{Orbital/ocular}

Different surgical procedures such as evisceration enucleation or an exenteration requires different prosthetic approach. Ocular prosthesis is simple as it replaces only the orbital contents, the eyelids are intact (Fig.5 a\&b). Orbital excenteration defects are most challenging to restore. Facial expression around the margin makes it difficult to achieve an accurate fit without the margins being lifted. Skin grafting with split thickness graft, sufficient depth for placement of components, minimum margin tissue distortion, preserving eyebrow position and rounded orbital margin helps to enhance the prognosis of the prosthesis. Placement of craniofacial implants for larger defects is generally located in the supraorbital rim or lateral rim of the residual orbit. Medial placement of the implant is discouraged due to diminished bone quantity and quality (Nishimura et al., 1998). It is always recommended for the patient to wear glasses to protect the natural eye and to camouflage the non-blinking prosthetic eye.

\subsubsection{Retention of extra oral facial prosthesis}

Achieving adequate retention for maxillofacial prosthesis is quiet an uphill task. The surgical procedures often sacrifice a large part of retentive feature. A wide range of retention methods are available depending on the requirement of an individual case, consideration should be given to the location and size of the defect, tissue mobility, undercuts and the material weight of the prosthesis, (Chalian, et.al. )The retention action can be broadly classified as Anatomical factors such as already existing on created undercuts areas/concavities etc.Limitation with its use is irradiated tissues, which should be spared of undue stress. The prosthesis may abrade the tissues causing ulceration. 


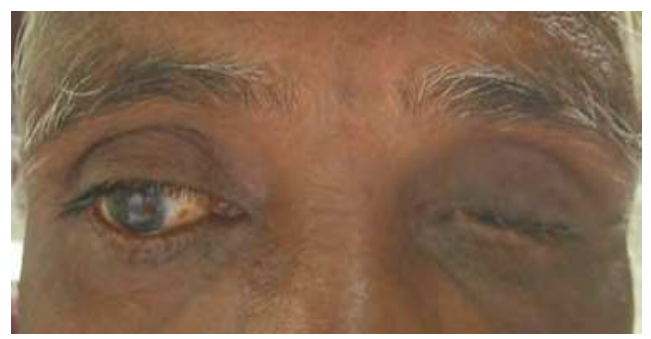

Ocular Defect

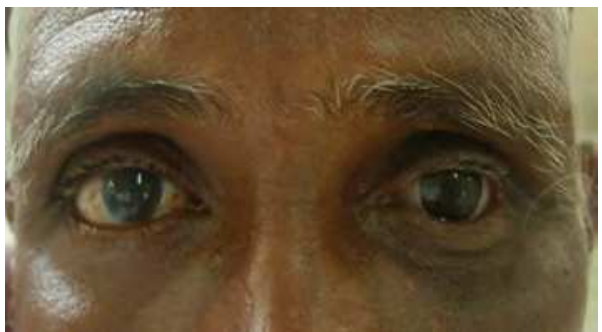

Ocular Prosthesis

Fig. 5. Ocular Defect Ocular Prosthesis

Mechanical retention by means of attachment to external devices such as eyeglasses, headbands or straps, stud clips, snap buttons, magnets.

Adhesives are simple and commonly used form of the retaining extraoral prosthesis. They are available in two common form liquid (Silicone or acrylic based) or double sided medical grade tape. Adhesive choice will depend on the material it will bond. There are limitations to adhesive retention methods. Movement of the skin around the prosthesis, high humidity, oily skin or profuse sweating will loosen the marginal seal and border adaptation of the prosthesis. Meticulous cleaning is required to prevent moisture build up and infection. Some patients may be allergic to the adhesives used. Other, most reliable form of retention when indicated is craniofacial implants.

Retention is a significant challenge in rehabilitation of maxillofacial defects necessitating careful planning, meticulous surgical technique and skillful prosthetic planning.

\section{Implants in maxillofacial prosthodontics}

Osseointegrated implants forms a fixed bone anchored retention method providing a stable platform for retaining an extraoral or intraoral prosthesis. It is defined as a process whereby clinically asymptomatic rigid fixation of alloplastic materials is achieved and maintained in bone during functional loading (Zarb, et al., 1991). Since their introduction in 1977 to support, a bone conduction hearing processor (Tjellstrom 1990) osseointegrated implants have superseded their application in maxillofacial prosthetic rehabilitation than any other forms of retention. The improved retention enhances functional and esthetic advantages in facial prosthesis, greater accuracy and a better marginal fit enabling the thinner margins blend more effectively will adjacent tissues. This is dictated by the amount, type and area of radiation including proper placement of implants and remaining hard and soft tissues contours post surgically.

Most implants used in maxillofacial prosthesis are made of titanium and are cylindrical. They are anchored in the bone using threads. The placement of implant usually requires two minor surgeries, with high precision and aseptic conditions. The first surgery is the insertion of titanium fixtures/ implants into the bone and osseointegration is allowed to occur 4-6 month in accordance with the bone quality. In the second surgery, the implants are uncovered and the retentive element called as abutment is placed on the implant (Parr, et.al. 
1981 as cited by Lemon, et al., 2005). The abutment can be used to hold a bar so that the prosthesis can be clipped into place or magnets can be used. Successful osseointegration depends on various factors. These include implant material biocompatibility, implant design and surface characteristics as well as surgical and loading conditions.

The introduction of advanced surgical procedures such as microvascular free tissue transfer has improved the treatment outcome. Free flap is an autogenous vascularized transplant, which involves the harvesting and detachment of bony and muscle tissue with its blood, and nerve supply and re-establishment by reanastomosis to suitable recipient site vessels (Mitchell, 2005 as cited by Fearraigh, 2009). Implants placed in the free flap reconstructed bone perform same as those placed in native bone. Use of implants in irradiated bone has been controversial. There is risk of developing Osteoradionecrosis of the mandible when carrying out surgical procedures such as implant placement. Certain factors needs consideration in placing implants in patients treated with radiation therapy for head and neck malignancies. The use of hyperbaric oxygen therapy (HBO) may help to revitalize the bone leading to improved success rate. It has been shown to prevent osteoradionecrosis in patients undergoing post radiation mandibular surgical procedures. The risk of ostcoradionecrosis is dependent on the radiation dose. Studies in the literature have suggested that an upper limit of 55 Gy should not be breached without the use of HBO. Disagreement as to when implants should be placed in irradiated bone remains. Zygomatic implants introduced by Branemark in 1988 are an alternative treatment modality to bone augmentation and sinus lift, where insufficient bone exists for maxillary implant placement (Kantas et al. 2002, Granstom, et al. 1992, Branemark 1998, Shaw, et al. 2005, as cited by Fearraigh P.O. et al. 2009).

\section{Use of prosthodontic splints and stents in radiotherapy}

Radiotherapy is increasingly being used in the management of head and neck cancer prior to or after surgery, either in combination with or without chemotherapy. Unfortunately, this treatment causes complications by increasing the morbidity of the surrounding tissues. This includes oral mucositis, infections, xerostomia, radiation caries, increased potential for osteoradionecrosis from infection (Fig.6a, b, c\&d) or trauma to irradiated bone, trismus, altered taste sensation etc.

As a preventive measure, or to minimize the severity of the side effects, radiotherapy protective devices/stents can be fabricated and used during the treatment (Kaanders, et al., 1992, Chambers, et al., 1995, Schaaf, 1984 as cited by Mantri, et al., 2010). These stents are used to protect or displace vital structures, locate diseased tissues in repeatable position during treatment, position the beam, carry radioactive material or as a dosimetric device to the tumor site, recontour tissues to simplify dosimetry and shield tissues. (Figure 7, 8 \&9) Before radiation treatment begins, flexible mouth trays can be fabricated which covers the teeth and are used to apply topical fluoride to prevent the onset of radiation induced tooth decay. Radiation of maxillary and hard palate tumors often includes the Temporomandibular joint and muscles of mastication, which causes stiffness of the joint, and fibrosis of the muscles followed by trismus, this can be minimized by oral exercises and use of appliances. 


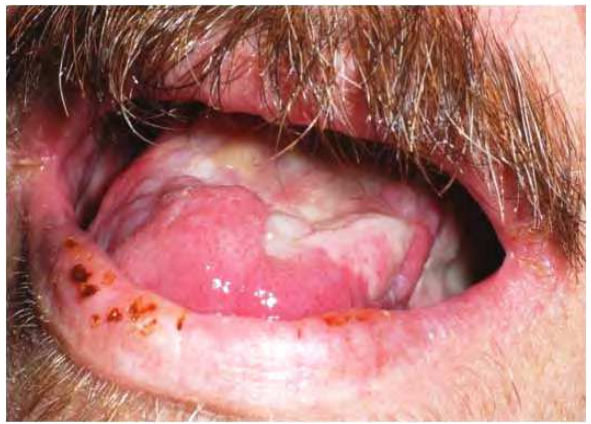

(a)

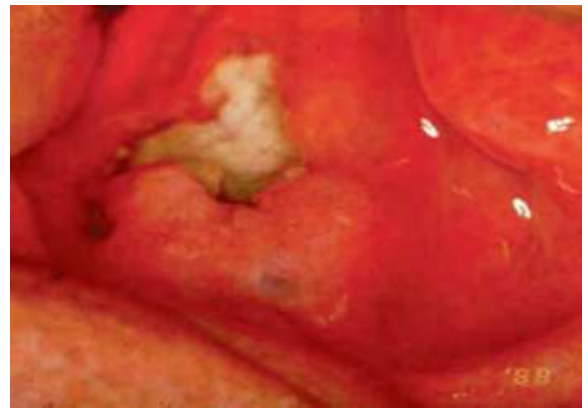

(c)

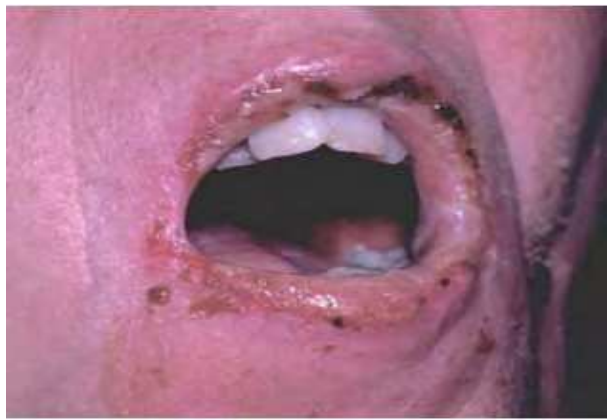

(b)

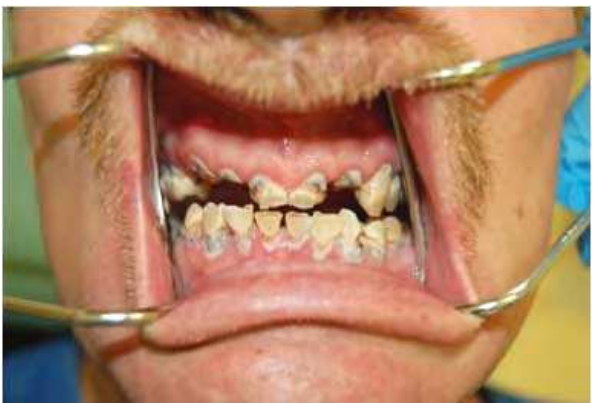

(d)

Fig. 6. a. Mucositis, post radiation showing desquamation of mucosa of dorsal surface of Tongue and Cheek. b. Keratitis of lips due to chemotherapy. c. Osteoradionecrosis showing ulceration, errythema of soft tissues, and bony sequestration. d. Radiation caries.

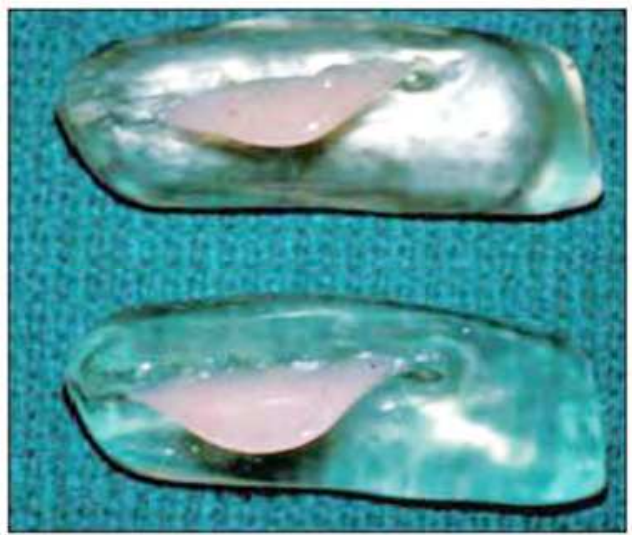

(a)

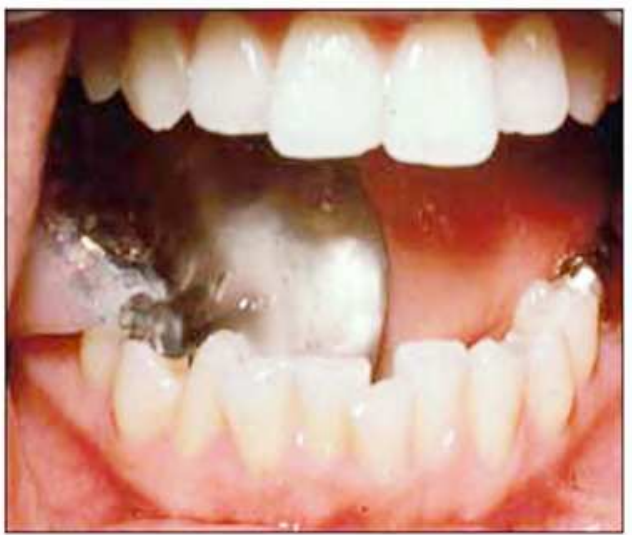

(b)

Fig. 7. (a) Intraoral lead shield for unilateral radiation (b) Shield in position in mouth protecting tongue and opposite side of the jaw. 

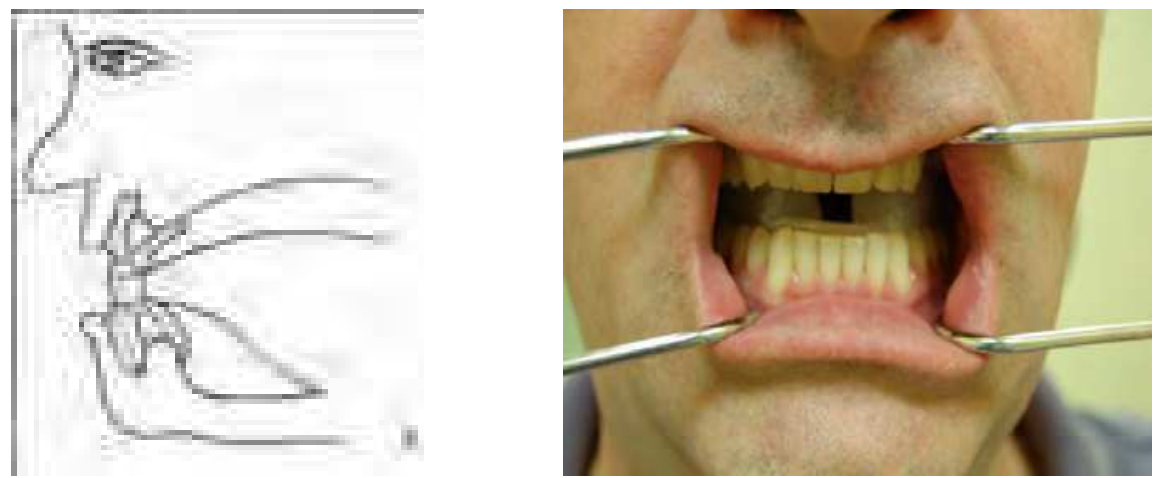

Fig. 8. Position maintaining stent

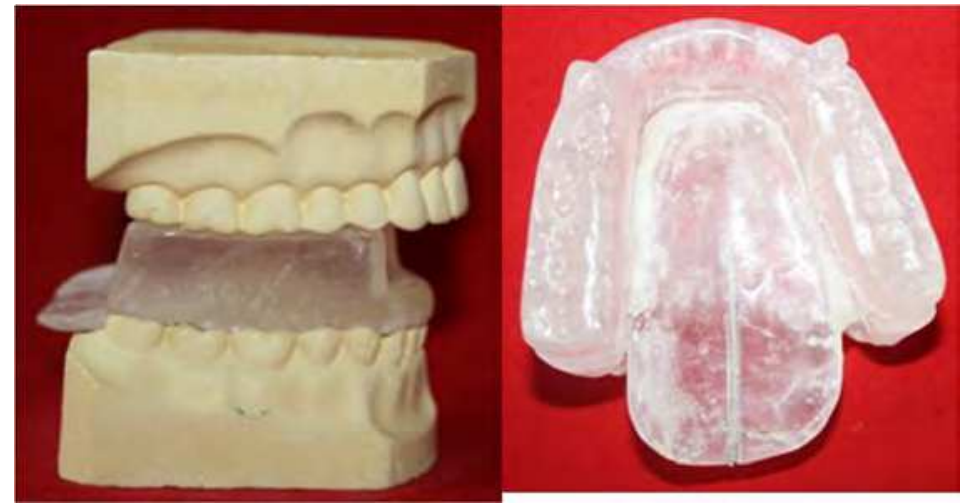

Fig. 9. Tongue depressing stent

Several prosthetic aids such as bite openers or exercises devices (Fig 10) can be used to help in the prevention of fibrosis of the muscles and to assist the patient in maintaining the mouth opening to eat and maintain oral hygiene.

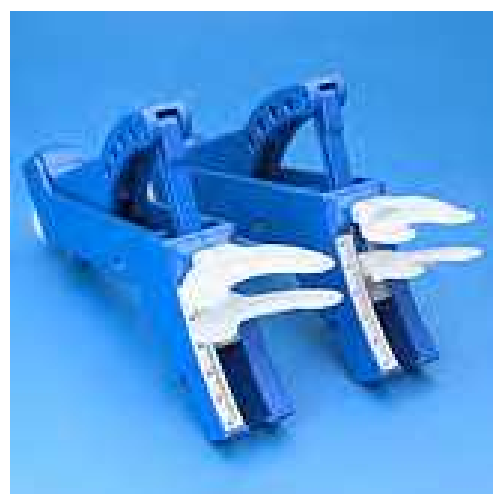

Fig. 10. Therabyte appliances for oral exercise 


\section{Patient education}

Communication and education is the key for accepting the prosthesis. Successful use of prosthesis may depend on the patient's psychological acceptance. Rehabilitation is not a passive process. The patient must be an active participant. Patients participation in the decision making process with realistic expectations is of vital significance. They should be educated about the treatment choices and convinced of their personal responsibilities towards the use and care of the prosthesis. The need for professional re-evaluation on a frequent periodic schedule should be emphasized to determine its adaptability to soft tissues, stability, retention, tissue receptivity, occlusion function and esthetics.

\section{Changing era in maxillofacial prosthetics}

The field of maxillofacial prosthetics is embracing the rapid explosion of technology. The use of ossoeointegrated implants has broadened the treatment options. New technologies offer standardized quality, excellent precision of fit and outstanding biocompatibility, combined with adequate mechanical strength and provision for esthetic design. Success of implants is based on precise preoperative planning of the implant placement and the restoration. Modern three-dimensional (3D) imaging techniques such as digital volume tomography allow the acquisition of radiologic data with very low levels of radiation and excellent image accuracy and allow the processing of these data with various types of soft -ware application. It is possible to predetermine the precise 3-D position of the planned implant before the actual insertion of implant and thus enhance the placement process. Treatment planned in this way is fast, minimally invasive and predictable. This increases the quality of surgical procedure and restoration (Marquardt, et.al. 2009). The advent and increasing availability of 3-D cone beam computerized tomography (CT) and 3-D digital panoramic imaging machines makes it easier, timely and less costly to obtain images (Angelopoulos et.al. 2011 as cited by Serio F.G. 2011) C.T. images are extremely useful as a visualization and diagnostic tool. The use of CT also allows for the discovery of other lesions of head and neck not visible by older imaging technique. Magnetic Resonance Imaging (MRI) is another technology, which is more sensitive than $\mathrm{CT}$ at showing the difference between soft tissue types and is a useful tool for detecting the early stages of abnormalities in soft tissues.

The introduction of laser technology, 3-D computer aided designing (3-D-CAD) and computer aided manufacturing (CAM) also known as rapid prototyping (RP) or free form fabrication has revolutionalized the field of maxillofacial technology. CAD /CAM technologies are capable of alleviating most of the limitations of conventional techniques. With rapid prototyping, a life like prosthesis can be fabricated. CAD/CAM technology is changing the restorative quality and concepts of the future. Hopefully the cost for using these technologies in maxillofacial prostheses will drop with time for more wide utilization.

Biological improvements and the regenerative possibilities for regaining lost bone have shown continued advancement in the use of growth factor and bone proteins including recombinant bone morphogenetic protein and helping the clinician's ability to provide bone for accurate implant placement.

Color matching of facial prosthetic elastomers to skin color with portable spectrophotometer and computerized color formulation has been developed and has achieved clinical success (Seelaus R et.al. 2000, Troppmann R.J. et.al. 1996 as cited by Wolfaardtt J. et.al. 2003). 
Relevant research on biomaterials advancement in surgical reconstruction such as microvascular free flap tissue transfers, bone-grafting methods have collectively helped to enhance rehabilitation outcomes.

\section{Future vision}

If the bridge between the existing chasm between oncology and rehabilitation has to be crossed several important challenges remains to be solved. Those challenges include 1) a paucity of outcome evaluation metrics 2) underdevelopment of the evidence base for cancer rehabilitation 3) the need for workforce development and 4) the absence of a health policy framework for cancer rehabilitation to support optimal service delivery, access to care and reimbursement (Mitchell S.A. 2010). Outcome is a major factor dictating treatment decisions and funding allocation. Quality of life outcome is equally important as survival rates. Those conducting research must ensure that evidence based research has its application to evidence based clinical practices. The reluctance to accept new treatment in clinical practice is a result of lack of adequate evidence. There is a need for transformation of educational programs. Core curriculum or competencies for cancer rehabilitation needs to be revised (Wolfaardtt et.al. 2003). The technological advancement as well as public demand for professionals accountability has increased the need for continuing and accessible education and specialized training for the professionals working with head and neck cancer patients. Interesting challenges are provided by robotics in the development of active prosthesis (Honda M. et.al. 1996, Klein M. et.al. 1999, as cited by Wolfaardt et.al. 2003) such as blinking and moving eye. Exciting developments in tissue engineering is likely to change the methods of reconstruction of tissue defects in the future. (Nusenbaum, et al., as cited by Kuriakose et al, 2007).Tissue engineering involves regeneration of new tissue with biologic mediators or scaffold. Success of tissue engineering depends on the effective participation of three components-scaffolds, signaling molecules and cells. Newer Scaffold materials with improved mechanical properties to provide tissue morphology and enhanced chemical properties to serve, as a bio-molecule carrier needs to be developed. Much research is being carried out in the field of muscular and neural tissue regeneration, which may have an impact in orofacial reconstruction in the future (Fearraigh, 2009).

Developing patient centered rehabilitation models, proposing evidence based guidelines through co-ordinated efforts of interdisciplinary teams should be on the agenda. Health policies to improve rehabilitation outcomes during and post surgical cancer treatment will be beneficial in rendering quality services to the cancer patient. Due to small number of newly diagnosed head and neck cancers in the United States, funding for research and development is limited. It is up to other countries where numbers are much greater to pursue this goal for helping these unfortunate patients. The economic impact of professional fees in maxillofacial prosthetics is difficult to summarize; since each case is unique and varies from region to region and country. It is also dictated by the treatment plan and the type of prosthesis. For example a nasal prosthesis retained by adhesive costs less than one retained by cranio-facial implants.

Restoration with a prosthesis is less expensive than plastic and reconstructive surgery.

Innovations in digital technology can be time saving and more precise but presently at significant cost for maxillofacial prosthesis. The investment in this technology should be based on subjective and objective assessment in terms of quantity and quality of outcome. 


\section{A flow chart of Maxillofacial Prosthesis}

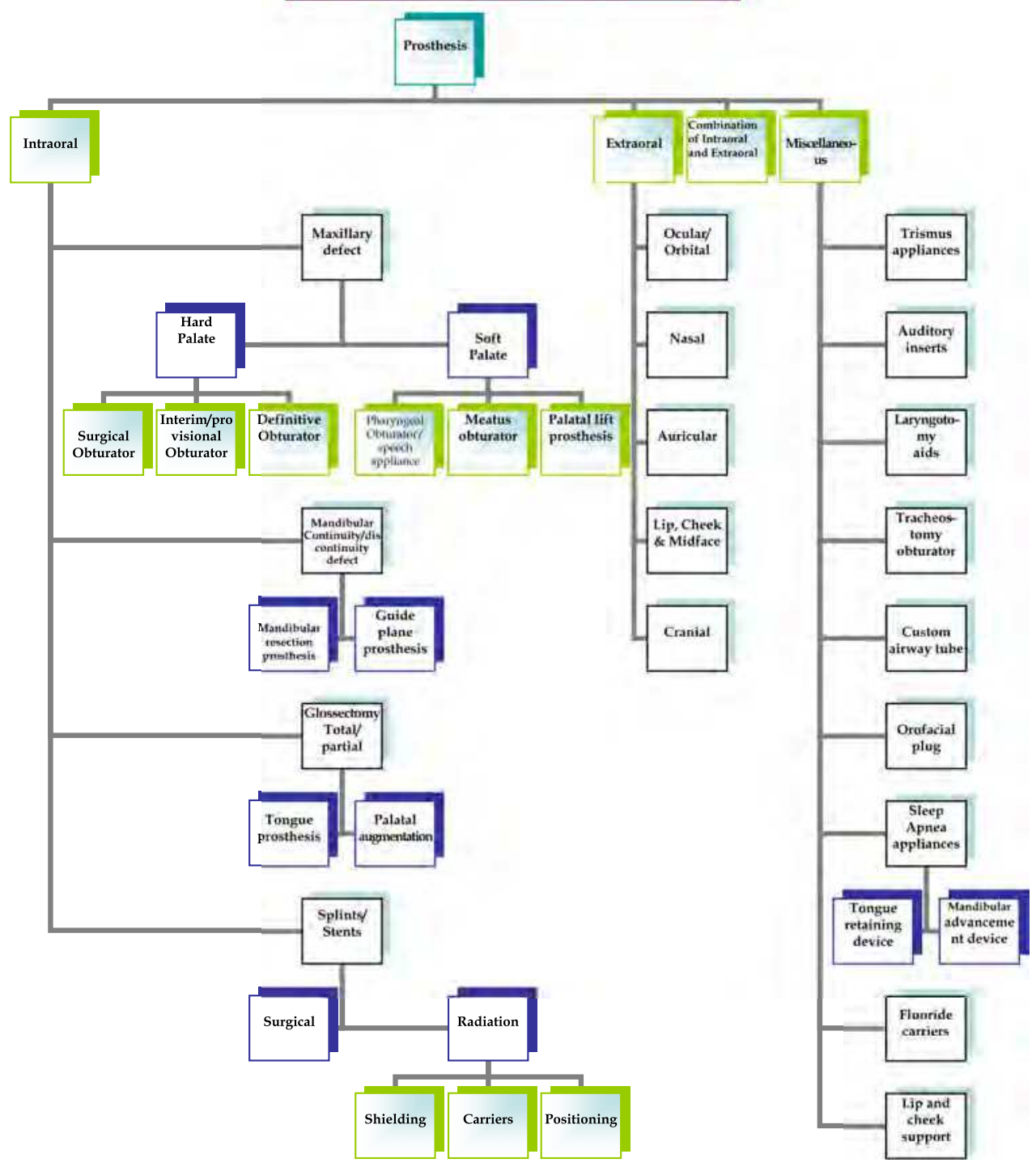

\section{Conclusion}

Rehabilitation of patients with acquired maxillofacial defects has always remained an enigma for the prosthodontist. The unpredictable nature of the defects and the uncertainty of recurrence have made the job of the prosthodontist more challenging. An attempt is made to discuss in brief the prosthetic aspects in rehabilitation of the patients with head and neck cancer. It stresses upon the need for multidisciplinary approach psychosocial consideration 
and the scope of prosthodontic services and the role of the maxillofacial prosthodontist in improving the QOL of such patients with different postsurgical defects. Although there are remarkable advances in technique and materials in past several years the full potential and utilization of maxillofacial prosthodontic services is yet not in sight. Today there is a need for dedicated and enthusiastic specialist coming forward and seeking specialized training for treating such patients. The integrated efforts, sound knowledge and practical implication in rehabilitating patients with acquired post surgical defects will help to bring smile and hope for patients with head and neck cancer now that longterm survival is achievable.

\section{References}

Andres. (1992) Survey of materials used in extraoral maxillofacial prosthetics. In Gettleman, L., Khan, Z. Eds. Proceedings of the conference on material research in maxillofacial prosthetics. Transactions of the Academy of Dental Materials. Vol. 5, pp. 25-40.

Andres, C.J. sss\& Haugh, S.P. (2000) Facial prosthesis fabrication: Technical aspects. In Clinical Maxillofacial prosthetics, Taylor, T.D., Ed, ISBN 086715-391-1, Illions.

Beumer, J. III \& Zlotolow, I. (1979) Restoration of facial defects, etiology, disability and rehabilitation. In Maxillofacial rehabilitation, Proshodontic and surgical considerations, Beumer, J., Curtis, T.A., Marunik, M.T., Eds. pp. 311-323, C.V. Mosby Company ISBN 0-8016-0676-4. USA.

Beumer, J., III, Zlotolow, I.M., \& Sharma, A.B. (2003) Restoration of Palate, Tongue, Mandible and facial defect, in Oral Cancer. Silverman, S., Ed., B.C. Deker Inc., ISBN 1-55009-215-4, Ontario.

Bonanno, A and Choi, J.Y. (2010) Mapping out the social experience of cancer patients with facial disfigurement, Health, Vol. 2, No. 5, pp. 18-24.

Breitbart, W. \& Holland, J. (1988) Psychological aspects of head and neck cancer. Semin Oncol, Vol. 15, pp 61-69.

Brown, K.E., (1970) Clinical Considerations in improving obturator treatment J. Prosthet Dent., Vol. 24, pp. 461-66.

Carr, A.B. (1998) Cosmetic and functional prosthetic rehabilitation of acquired defects. In OtolaryngologyHeadandNecksurgery, Vol.1, 3rdedition, Cummings, C.W., Fredrickson, J.M., Harker, L.A., et al Eds, Mosby Publication, pp. 1612-1634.

Chalian, V.A., Drane, J.B. \& Standish, S.M. (1972) The Evolution and Scope of Maxillofacial prosthetics. In Maxillofacial prosthetics Multidisciplinary Practice. Chalian, V.A., Drane, J.B. and Standish, S.M. Eds., the Williams \& Wilkins Company, ISBN 10:0683015125, Baltimore, USA.

Chalian, V.A., Bogan, R.L. and Snadlewick, J.W. (1972) Retention of Prosthesis. In Maxillofacial Prosthetics Multidisciplinary Practice. Chalian, V.A., Drane, J.B. \& Standish, S.M., Eds., pp. 121-132, The Williams and Wilkins Company, ISBN 10:0683015125 Baltimore, USA.

Davenport, J. (1996) Managing the prosthetic rehabilitation of patient with head and neck cancer. Dent. News, Vol., 3, No.3, pp. 7-11.

Desjardins, R.P. (1978) Obturator prosthesis design for acquired maxillary defects. J. Prosthet Dent., Vol. 39, pp. 424-25. 
Dingman, C., Hegedus, P.D., Likes, C., McDowell, P., McCarthy, E., \& Zwilling, C. (2008) A Co-ordinated Multidisciplinary approach to caring for the patients will head and neck cancer. J. Support Oncol, Vol. 6, No.3, pp. 125-131.

Eckert, S.E., Desjardins, R.P. and Taylor, T.D. (2000) Clinical Management of the soft palate defect. In Clinical Maxillofacial Prosthetics, Taylor, T.D., Ed., pp. 121-132, Quintessence Publishing Co.Inc. ISBN 0-86715-391-1, Illinois.

Fearraigh, P.O. (2009) Review of Methods used in the reconstruction and rehabilitation of the maxillofacial region, J. of the Irish Dental Association. Vol. 56, No.1, 3237.

Gibbons, P. \& Bloomber, H. (1958) A supportive type prosthetic speech aid. J. prosthetic, Dent. Vol. 8, 362-374.

Gillis, R.E. (1979) Psychological Implications of patient care. In maxillofacial prosthetics, Laney, W.R. \&, Gardner, A.F., Eds., pp. 21-40, P.S.G. Publication Company, ISBN 0884161609,Michigan.

Gonzalez, T.B. \& Aranson, A.E. (1970) Palatal lift prosthesis for treatment of anatomic and neurologic palatal insufficiency. Cleft Palate Journal, Vol., 7, pp. 91-104.

Haman, K.L. (2008) Psychological distress, head, and neck cancer, Part 1- Review of the literature. J Support Oncol. Vol. 6, No.4, April 2008, pp. 155-163.

Hearst, D. (2007) Can't they like me as I am? Psychological intervention for children and young people with congenital disfigurement. Dev. Neurorehab., Vol. 10, No.2, pp. 105-12.

Hubalkowa, H., Holakovsky, J., Bradza, F. Diblik, P. \& Mazenek, J. (2010) Team approach in the treatment of extensive maxillofacial defects. Five case report series. Prague Medical Report, Vol. 111, No.2, pp. 148-157.

Huryn, J.M. Piro, J.D. (1989) The maxillary immediate Surgical Obturator Prosthesis. J. Prosthet Dent, Vol. 61, pp. 343-47.

Jacob, R.F. (2000) Clinical Management of the Edentulous Maxillectomy patient. In Clinical Maxillofacial Prosthetics, Taylor, T.D. Ed., pp. 85-102. Quintessence Publishing Co., ISBN 0-86715-39-1 Illinois.

Jerbi, F.C., Ramey, W.O., Drane, J.B., Margetis, P., Lebley, J.P., \& Goepp, R.A., et.al. (1968) Prostheses, stents and splints for the oral cancer patients. CA: A Cancer Journal Clinicians, Vol. 18, No. 6, pp 327-352.

Keyf, F. (2001) Obturator prosthesis for hemimaxillectomy patients. J.Oral Rehab. Vol. 28, pp. 821-29

Khan,Z.,Gettleman,L. \& Jacbson,C (1992) Conference Report: Material Research in Maxillofacial Prosthetics Dent Res.,Vol.71,pp1541.

Khan, Z. \& Farman, A.G. (2006) The prosthodontist role in head and neck cancer and introduction - Oncologic dentistry. J. Ind Prosthodont. Soc., Vol. 6, No.1, pp. 4-9.

Kuriakose, M.A., Sharma, M., \&Ivyer, S. (2007) Recent advances and controversies in head and neck reconstructive surgery. Indian journal of Plastic Surgery.Vol.40, No.12, pp.3-12.

Laaksonen, J.P., Lowen, I.J., Wolfaardt, J., Rieger, J., Seikalay, H. \& Harris, J. (2009) Speech after tongue reconstruction and use of a palatal Augmentation prosthesis. An acoustic case study. Canadian Journal of speech- language pathology and Audiology. Vol. 33, No. 4, pp. 196-202. 
Lemon, J.C. Martin, J.W., \& Jacob R.F. Prosthetic rehabilitation. In: Basal and squammous cell skin cancers of head and neck. Weber, R.S., Miller, M.J., Goepfert H., eds., pp. 305-312, Williams \&Wilkins.

Lemon, J.C., Martin, J.W., Chambers, M.S., Kiat amnuay, S. Gettleman L. (2005) Facial prosthetic rehabilitation, preprosthetic surgical techniques and biomaterials. Curr. Opin. Otolaryngol head neck surg. Vol. 13, pp. 255-262, ISSN 1068-9508.

Logman, J.A. (1998) Rehabilitation for the head and neck cancer patient, oncology, vol. 10, No. 1,

Pascal, M., Siegbert, W. \& Strub, J. (2007) Three-dimensional navigation in implant dentistry. Euro, J. Oral Implantology, Vol. 2, No.1

Mantri, S.S., Bhasin, A.S. (2010) Preventive Prosthodontics for Head and Neck Radiotherapy. Journal of Clinical and Diagnostic Research. 2010 August, Vol.4, pp.2958-62.

Maureen S. (2004). The expanding role of dental oncology in head and neck surgery.Surg Oncol Clin N Am.Vol.13, 37-46.

Mitchell, S.A. (2010) Framing the challenges of cancer Rehabilitation. Oncology Nurse Edition, Vol. 24, No.1, Suppl. pp. 33-4.

Moser, V.F., Crevenna, R., Korpan M. \& Quiltan, M. (2003) Cancer Rehabilitation particularly with aspects of physical impairment J. Rehab Med. Vol. 35, pp. 153-162.

Nishimura, R.D., Roumanas, E., Moy, P.R., Suga, T., \& Freymiller, E.G. (1998) Osseointegrated implants and orb ital defects: U.C.L.A. experience. J. Prosthet Dent., vol.79, no.3, pp.304-9.

Odell, M.J. and Gullane, P.J. (2007) Partial and total maxillectomy. In Lee, K.J. and Toh, E.H. Eds. Otolaryngology: A Surgical note book, pp 236-256. Thieme Medical Publishers ISSN 9783131383518 New York.

Roger, S.N. (2010) Quality of life perspective in patients with oral cancer. Oral Oncology, Vol. 46, pp. 445-47.

Tjellstrom, A. (1990) Osserintegrated implants for replacement of absent or defective ears. Clin. Plast. Surg. Vol. 17, pp 355-366.

Tuna, S.H., Pekkan, G., Gumus, H.O. \& Aktas A. (2010) Prosthetic Rehabilitation of Velopharyngeal Insufficiency: Pharyngeal Obturator Prostheses with different retention Mechanisms. Eur J. Dent, Vol. 4, No.1, pp. 81-87.

Van Doorne, J.M. (1994) Extraoral Prosthetics: Past and Present. J Investigative Surg. Vol. 7, No. 4, 267-74.

Wallace, C.G. \& Wei, F.C. (2008) The status, Evolution and future of facial Reconstruction. Chang Gung Med J. Vol. 31, No.5, 441-9.

Wang, R.R. (1997) Sectional prosthesis for total maxillectomy patient. A clinical report J. Prosthet Dent. Vol.78, No.3, pp. 241-244.

Wolfaardt, J. Gehl, G., Farmand, M. \&Wilkes, G. (2003) Indication and methods of care for aspects of extraoral osseointegration 32:124-137.

Wolfaardt, J. et al. (2003) Advanced technology and the future of facial prosthetics in head and neck reconstruction. Int. J. Oral Maxillofacial Surg. Vol. 32, pp. 121-123.

Yoshida, H., Furuya, Y., Shimodaira, K., Kanazawa, T. \& Kataoka, R. \& Takahashi, K. (2000) Spectral characteristics of hypernasatity in maxillectomy patients. J. of Oral Rehab. Vol. 27, pp. 723-730.

Zarb, G.A. and Albrektsson, T. (1991) Osseointegration a requiem for the periodontal ligament. Int. J. Periodontics, Rest Dent., Vol. 11, pp. 88-91. 
Zaki, H.S. (2000) Prosthodontic Rehabilitation following total and partial glossectomy. In: Clinical Maxillofacial Prosthetics. Taylor, T.D. Ed pp. 205-214, Quintessence Publication Co., ISBN 0-86715-39-1. Illinois.

Zlotolow, I.M. (2001) Dental Oncology and Maxillofacial Prosthetics. In Atlas of Clinical Oncology. Cancer of the Head and Neck pp. 376-373.,Shah, J.P. ed.,B C Decker Inc, ISBN 1-55oo9-084-4,Ontario. 


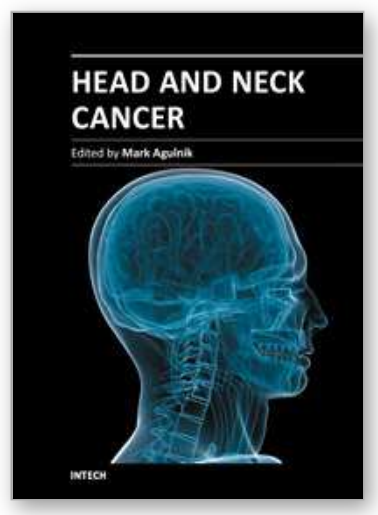

\author{
Head and Neck Cancer \\ Edited by Dr. Mark Agulnik
}

ISBN 978-953-51-0236-6

Hard cover, 440 pages

Publisher InTech

Published online 14, March, 2012

Published in print edition March, 2012

Head and Neck Cancer provides an interesting and comprehensive overview of all aspects of head and neck cancer including overviews of the disease, basic science aspects pertaining to the disease, diagnosis,

treatment and outcomes for patients with this disease. The chapters written by world renowned experts cover the entire discipline of head and neck oncology and include discussions of regional disparity is, advances in basic science understanding, advances in her radiotherapy, chemotherapy and targeted agents as well as a focus on reconstruction, prostheses, and aspects of quality of life and health outcomes. The book is designed to be both practical and comprehensive for every physician treating his complex disease.

\title{
How to reference
}

In order to correctly reference this scholarly work, feel free to copy and paste the following:

Sneha Mantri and Zafrulla Khan (2012). Prosthodontic Rehabilitation of Acquired Maxillofacial Defects, Head and Neck Cancer, Dr. Mark Agulnik (Ed.), ISBN: 978-953-51-0236-6, InTech, Available from:

http://www.intechopen.com/books/head-and-neck-cancer/prosthodontic-rehabilitation-of-acquiredmaxillofacial-defects

\section{INTECH}

open science | open minds

\section{InTech Europe}

University Campus STeP Ri

Slavka Krautzeka 83/A

51000 Rijeka, Croatia

Phone: +385 (51) 770447

Fax: +385 (51) 686166

www.intechopen.com

\section{InTech China}

Unit 405, Office Block, Hotel Equatorial Shanghai

No.65, Yan An Road (West), Shanghai, 200040, China

中国上海市延安西路65号上海国际贵都大饭店办公楼405单元

Phone: +86-21-62489820

Fax: +86-21-62489821 
(C) 2012 The Author(s). Licensee IntechOpen. This is an open access article distributed under the terms of the Creative Commons Attribution 3.0 License, which permits unrestricted use, distribution, and reproduction in any medium, provided the original work is properly cited. 